\title{
Glucocorticoid receptor expression on circulating leukocytes in healthy and asthmatic adolescents in response to exercise
}

\author{
Kim D. Lu', Dan Cooper ${ }^{1}$, Fadia Haddad', Frank Zaldivar ${ }^{1}$, Monica Kraft ${ }^{2}$ and Shlomit Radom-Aizik ${ }^{1}$
}

BACKGROUND: Poor aerobic fitness is associated with worsening of asthma symptoms, and fitness training may improve asthma control. The mechanism linking fitness with asthma is not known. We hypothesized that repeated bouts of exercise would lead to a downregulation of glucocorticoid receptor (GR) expression on circulating leukocytes, reflecting a reduced responsiveness to stress.

METHODS: In a prospective exercise training intervention of healthy and asthmatic adolescents, GR expression in leukocytes was measured using flow cytometry in response to an acute exercise challenge before and after the exercise training intervention. Peripheral blood mononuclear cell (PBMC) gene expression of GR, GR $\beta, H S P 70, T G F \beta 1$, and TGF $\beta 2$ was determined using reverse-transcriptase PCR (RT-PCR).

RESULTS: Peak $\mathrm{VO}_{2}$ increased by $14.6 \pm 2.3 \%$, indicating an effective training $(P<0.01)$. There was a significant difference in GR expression among leukocyte subtypes, with highest expression in eosinophils. Following the exercise training intervention, there was a significant decrease in baseline GR expression $(P<0.05)$ in leukocyte and monocyte subtypes in both healthy and asthmatic adolescents.

CONCLUSIONS: This is the first study in adolescents to show that exercise training reduces GR expression in circulating leukocytes. We speculate that exercise training downregulates the stress response in general, manifested by decreased GR expression, and may explain why improving fitness improves asthma health.

$T^{1}$ he mechanisms of exercise-associated bronchoconstriction (EIB) in asthma remain enigmatic. Earlier research suggested that brief exercise leads to sudden water loss and temperature reduction in the airways, triggering bronchoconstriction; however, these specific physicochemical exercise responses occur similarly in people both with and without a history of asthma (1). Why these airway perturbations lead to bronchoconstriction in susceptible individuals is not clear. In a previous study, we induced ovalbumin (OVA) sensitivity in rats by parenteral OVA and then exposed the animals to aerosolized OVA or exercise. Bronchoconstriction resulted not only from specific exposure to aerosolized OVA, an expected finding in the previously sensitized rats, but, intriguingly, also from nonspecific exposure to brief exercise (2). These results add to the evidence that there is an exerciseassociated inflammatory mechanism in EIB.

A brief bout of exercise leads to marked increases in circulating leukocytes in children and adults, and alters leukocyte gene expression (3). The pattern of circulatory mediators that changes after acute exercise (e.g., the increase in both cortisol and interleukin 1 receptor antagonist) suggests a highly regulated inflammatory response in which both proand anti-inflammatory processes are activated (4). Stressful and inflammatory states and diseases cause a downregulation of leukocyte glucocorticoid receptor (GR) (5), and Bonifazi et al. (6) showed that highly trained athletes had reduced GR expression in peripheral blood mononuclear cells (PBMCs).

The goal of this research was to test the immediate impact of an acute exercise challenge and the longer-term effect of an 8 -week-exercise training intervention on GR expression in circulating leukocytes in adolescents with and without asthma. We undertook this exploratory study to better understand (i) why brief exercise is a major trigger of bronchoconstriction in children with asthma and (ii) somewhat paradoxically, why physical fitness is associated with better asthma control across the lifespan $(7,8)$. Circulating leukocytes have a mechanistic role in the pathogenesis of bronchoconstriction (9), and acute exercise challenges alter gene expression and function of many asthma-related pathways in circulating leukocytes (3). These observations led us to hypothesize that acute exercise challenges and exercise training would affect leukocyte GR expression, a gateway and control point for the many stress and inflammatory functions associated with asthma (10).

In the present study, we examined for the first time the impact of both acute exercise and an exercise training intervention on leukocyte GR protein expression (using flow cytometry) and gene expression (reverse-transcriptase PCR (RT-PCR)) in adolescents with and without asthma. Moreover, as the gene expression response to exercise varies among the leukocyte subtypes $(3,11)$, we isolated and separately identified the exercise effect on monocytes, neutrophils, eosinophils, basophils, and lymphocytes.

\footnotetext{
${ }^{1}$ Department of Pediatrics, Pediatric Exercise and Genomics Research Center, University of California Irvine School of Medicine, Irvine, California; ${ }^{2}$ Department of Medicine, University of Arizona Health Sciences Center, Tucson, Arizona. Correspondence: Kim D. Lu (kdlu@uci.edu)

Received 17 October 2016; accepted 4 March 2017; advance online publication 21 June 2017. doi:10.1038/pr.2017.66
} 
Acute exercise is often used as an aid in the diagnosis or characterization of asthma. Although such challenges are highly specific, their sensitivity (using most current protocols) is poor. Why many asthmatic adults and children with a convincing history of exercise-induced bronchoconstriction do not manifest airway obstruction during in-laboratory testing remains enigmatic. Nonetheless, we did measure standardized pulmonary function before and after the acute exercise challenges and evaluated other gas exchange markers of airway function (e.g., the relationship between ventilation $(\dot{\mathrm{VE}})$ and $\mathrm{CO}_{2}$ production $\left(\dot{\mathrm{V} C O}{ }_{2}\right)$ during exercise (12)).

\section{METHODS}

\section{Subjects}

Fourteen healthy and twelve asthmatic adolescents (aged 14-17 years) participated in the study. Girls were not pregnant. Elite athletes and individuals who participated vigorously in competitive sports were excluded from participation. This study was approved by the institutional review board for human research at the University of California, Irvine, and informed consent was obtained from all subjects.

\section{Anthropometric Measurements}

Standard, calibrated scales and stadiometers were used to determine height and body mass. Dual X-ray absorptiometry was used to determine body composition, including LBM and percent body fat, using a Hologic QDR 4500 densitiometer (Hologic, Bedford, MA). Dual X-ray absorptiometry scans were performed and analyzed using a pediatric software.

\section{Pulmonary Function Testing}

Spirometry was performed at baseline and 10-15 min after exercise challenge. Spirometry included forced vital capacity (FVC) and forced expiratory volume in 1 second $\left(\mathrm{FEV}_{1}\right)$ measured in triplicate $\left(V_{\max } 229\right.$; Sensormedics, Yorba Linda, CA) according to American Thoracic Society guidelines (13). If participants had $\geqslant 10 \%$ decrease in $\mathrm{FEV}_{1}$ following acute exercise challenge, then inhalation of albuterol was given and spirometry was repeated. All medications, including inhaled corticosteroids, were held for at least $24 \mathrm{~h}$ prior to each visit.

Asthma control was assessed using the Asthma Control Questionnaire (ACQ) (14) before and after the exercise training intervention in participants with asthma.

\section{Exercise Training Intervention}

Participants completed an 8-week aerobic exercise training intervention ( 1 -h session, 3 days a week). Three asthmatic participants did not complete the exercise training intervention due to transportation or personal issues. The participants performed a fitness assessment and an acute exercise challenge before and after the exercise training intervention.

\section{Fitness Assessment}

Each subject performed a ramp-type progressive cycle ergometer exercise test using the SensorMedics metabolic system (Ergoline $800 \mathrm{~S}$, Yorba Linda). After sitting comfortably without pedaling ("resting") on the cycle ergometer for 3 and $1 \mathrm{~min}$ of unloaded pedaling, the work rate (WR) was incremented at $10-20 \mathrm{~W} / \mathrm{min}$ to the limit of the subject's tolerance. The subjects were vigorously encouraged during the high-intensity phases of the exercise protocol. Gas exchange was measured breath-by-breath and peak $\mathrm{VO}_{2}$ was calculated as the highest $20 \mathrm{~s}$ rolling average in the last minute of exercise. Respiratory anaerobic threshold was calculated using standard methods (15).

\section{Acute Exercise Challenge and Blood Draws}

At least $48 \mathrm{~h}$, but not exceeding 7 days, following the completion of the ramp test, each subject performed 20 min of exercise consisting of 102 -min bouts of constant WR cycle ergometry, with 1-min rest interval between each bout of exercise (i.e., a 30-min interval). The WR was individualized for each subject and was calculated to be equivalent to the $\mathrm{WR}$, corresponding roughly to $50 \%$ of the WR between the respiratory anaerobic threshold and the peak oxygen uptake. On average, this WR was equivalent to $75 \%$ of the participants' peak $\mathrm{VO}_{2}$. Blood was drawn prior to, immediately after exercise, and $1 \mathrm{~h}$ into recovery.

\section{Blood Sample Collection}

Two 10-ml EDTA blood samples were obtained before and immediately after the acute exercise challenge and $1 \mathrm{~h}$ into recovery. One $\mathrm{ml}$ whole blood was sent to UCI-Clinical Pathology Laboratory for complete blood count with differential. Two $\mathrm{ml}$ whole blood was aliquoted to be used immediately for leukocyte immunophenotyping and intracellular staining of the GR using flow cytometry. The remaining blood was used to separate plasma for cortisol and cytokine analysis. A second $10 \mathrm{ml}$ EDTA-treated peripheral blood was collected to isolate PBMC on a subset of healthy and asthmatic adolescents. Plasma lactate was measured before and after exercise using YSI 2300 STAT Plus Glucose and Lactate Analyzer (YSI Life Science, Yellow Springs, OH, USA).

\section{Flow Cytometry}

Whole blood was used for surface immunophenotyping using surface marker antibodies and intracellular GR determination. GR expression is expressed as median fluorescence intensity (MFI).

The following surface antigen-specific fluorescent-conjugated monoclonal antibodies were used in multiparameter flow cytometry: CD14-PerCP (clone MФP9, BD Biosciences, San Jose, CA), CD3APC (clone UCHTI), CD16-Pacific Blue (clone 3G8), CD193-APC (clone 5E8), and CD203-APC (clone NP4D6), all from Biolegend (San Diego, CA). Details of the protocol as well as acquisition and analysis of the flow cytometry data including representative flow cytometry plots can be found in the Supplementary Materials online) including Supplementary Figure S1.

\section{Gene Expression}

On a subset of 10 healthy and 11 asthmatic participants, PBMC gene expression of the GR (NR3C1) and selected genes known to be involved in the GR pathway (GR $\beta$, TGF $\beta 1$, TGF $\beta 2$, and heat shock protein $70 \mathrm{kD}(16-18)$ ) was performed using RT-PCR.

GR $\alpha$, the active isoform, and GR $\beta$, an isoform that is thought to act as a dominant-negative inhibitor, are formed after alternative splicing. Elevated levels of GR $\beta$ are associated with glucocorticoid resistance in several conditions, including asthma (17). HSP70 is affected by acute bouts of exercise and also interacts with GR through partial unfolding, which results in GR ligand release and inactivation (16). TGF $\beta 1$ and TGF $\beta 2$ are involved in pathogenesis of inflammation in asthma and are inhibited by glucocorticoids (18).

In a series of previous studies in our laboratory, we examined the impact of acute bouts of exercise on gene expression in circulating subtypes of leukocytes using very stringent statistical requirements $(3,11,19)$. We have found $\sim 2,000$ genes influenced by exercise. We then interrogated these gene sets to see whether there was an overlap with genes known to be affected by GR. In previously published data from this and other laboratories, we identified a set of common genes related to the GR regulatory network and acute exercise in circulating monocytes (Table 1). The genes that we found appear to have pivotal roles in both exercise and GR function, and will be tested in future studies. Please see Supplementary Material for details of PMBC isolation and RT-PCR. 
Table 1. Common genes in monocytes altered in response to acute exercise and associated with the GR pathway

\begin{tabular}{|c|c|c|c|}
\hline Gene symbol & Gene name & Change & Relevant function \\
\hline$N R 3 C 1$ & $\begin{array}{l}\text { Nuclear receptor subfamily } 3 \text {, } \\
\text { group } C \text {, member } 1\end{array}$ & $\uparrow$ & $\begin{array}{l}\text { Glucocorticoid receptor. It is critical in inflammatory response, cellular proliferation, and } \\
\text { differentiation in target tissues }\end{array}$ \\
\hline NR4A1 & $\begin{array}{l}\text { Nuclear receptor subfamily } 4 \text {, } \\
\text { group } A \text {, member } 1\end{array}$ & $\uparrow$ & $\begin{array}{l}\text { Involved in cellular response to } \mathrm{CRH} \text {, fat cell differentiation, negative regulation of cell } \\
\text { cycle, apoptosis, and skeletal muscle cell differentiation }\end{array}$ \\
\hline FKBP4 & FK506-binding protein 4, $59 \mathrm{kDa}$ & $\uparrow$ & $\begin{array}{l}\text { Involved in immunoregulation, intracellular trafficking of steroid hormone receptors, } \\
\text { steroid hormone receptor complex assembly, protein folding, and androgen receptor } \\
\text { signaling pathway }\end{array}$ \\
\hline HSP90AA1 & $\begin{array}{l}\text { Heat shock protein } 90 \mathrm{kDa} \text { alpha, } \\
\text { class A member } 1\end{array}$ & $\uparrow$ & $\begin{array}{l}\text { Chaperone protein that promotes maturation, structural maintenance, and proper } \\
\text { regulation of specific target proteins. Also involved with protein folding/response to } \\
\text { stress }\end{array}$ \\
\hline$P B X 1$ & Pre-B-cell leukemia homeobox 1 & $\downarrow$ & $\begin{array}{l}\text { May be involved in regulation of osteogenesis, skeletal patterning, and programming. } \\
\text { May also have a role in steroidogenesis and sexual differentiation }\end{array}$ \\
\hline FKBP5 & FK506-binding protein 5 & $\downarrow$ & $\begin{array}{l}\text { Has a role in immunoregulation and basic cellular processes involving protein folding } \\
\text { and trafficking. Also involved in glucocorticoid resistance }\end{array}$ \\
\hline
\end{tabular}

$\mathrm{BMI}$, body mass index; GR, glucocorticoid receptor.

www.genecards.org

\section{Cortisol}

Plasma cortisol was determined by enzyme immunoassay using a commercial ELISA kit (Rocky Mountain Diagnostics, Colorado Springs, CO). All samples were analyzed in duplicate following the manufacturer's protocol. Our laboratory reports a coefficient of variation $(\mathrm{CV})<10 \%$ on all samples evaluated-inter-assay $\mathrm{CV}$ (four plates $)<10 \%$ and intra-assay $\mathrm{CV}<10 \%$.

\section{Statistical Analysis}

Data were analyzed using the SAS 9.4 software (SAS Institute, Cary, NC). Two different mixed model analyses were conducted. The primary analysis evaluating differences in MFI intensity for GR expression among leukocyte subtypes utilized a mixed random effects model, taking into account the subject-level intercorrelation. This model included exercise training, sex, group (healthy vs. asthma) main effects, and interactions. Next, a set of models accounting for subject intercorrelations among repeated measures was run within each leukocyte subtype, evaluating differences related to acute exercise challenge and exercise training, sex, and group (healthy vs. asthma). Secondary analyses included a set of models evaluating acute exercise and exercise training effects on absolute leukocyte subtype counts. Post hoc mean comparisons were adjusted for multiple comparisons using a Tukey-Kramer adjustment, and effect sizes were also evaluated. Differences in the mean relative quantification (RQ) of selected genes before and after exercise training were assessed using a non-paired $t$-test. $P$ value of $<0.05$ was considered significant.

\section{RESULTS}

\section{Anthropometric, Fitness, and Spirometry Data}

Subjects were eight healthy males, six healthy females, four asthmatic males, and eight asthmatic females, 14-17 years of age (Table 2). There were no significant differences in BMI percentiles or body composition between healthy and asthmatic participants except for lean body mass (LBM) among males. Asthmatic males had a mean LBM of $60.9 \pm 5.3 \mathrm{~kg}$ compared with healthy males with a mean LBM of $47 \pm 6.5 \mathrm{~kg}$ at baseline.

Spirometry was similar between healthy and asthmatic participants except for FVC \% predicted. Asthmatics had a mean FVC \% predicted of $110 \pm 12.9 \%$ compared with healthy participants with a mean FVC \% predicted of
$95.3 \pm 10.2 \%(P<0.05)$. Two participants with asthma met the criteria for exercise-induced bronchoconstriction with $\geqslant 10 \%$ drop in $\mathrm{FEV}_{1}$ following acute exercise challenge prior to exercise training intervention (20). One of the two participants did not have EIB following acute exercise challenge after exercise training intervention, and the other participant dropped out.

\section{Asthma Control}

Six of the twelve participants with asthma had persistent asthma per NAEPP criteria (21) and were on daily controller medications. Two of the participants had uncontrolled asthma as per the Asthma Control Questionnaire (ACQ, score $\geqslant 1.50$ ) at baseline. There was no significant difference in the mean ACQ score following exercise training among the participants with asthma (Table 2). However, two of the participants had significant improvement in ACQ following training (change score of $\geqslant 0.5$ ), whereas one participant had a worsening ACQ score following training.

\section{Acute Exercise Challenge}

There was a significant increase in lactate following acute exercise challenge, with a mean lactate of $2.1 \pm 0.1 \mathrm{mmol} / \mathrm{L}$ at baseline to a mean lactate of $9.5 \pm 0.5 \mathrm{mmol} / \mathrm{L}$ following exercise (Figure 1; $P<0.001$ ). There was no significant difference in lactate response to acute exercise following exercise training $(P=0.74)$, even though peak $\dot{\mathrm{VO}}_{2}$ and $\mathrm{WR}$ were higher following exercise training.

There was no difference in exercise $\Delta \dot{\mathrm{V} E} / \Delta \dot{\mathrm{V}} \mathrm{CO}_{2}$ between healthy and asthmatic participants before or after the exercise training intervention (Table 2).

\section{Exercise Training Intervention}

Eighty-eight percent of participants completed the 8-week aerobic exercise training intervention. Peak $\dot{\mathrm{VO}}_{2}$ did not differ between healthy and asthmatic participants at baseline by sex. Peak $\mathrm{VO}_{2}$ increased by a mean of $14.6 \pm 2.3 \%$ among all 


\section{Articles | tu et al.}

Table 2. Baseline characteristics of participants

\begin{tabular}{|c|c|c|}
\hline & Healthy, $n=14$ (8 males) & Asthmatics, $n=12$ (4 males) \\
\hline Age in years, mean (range) & $15.0(14-17)$ & $15.7(14-17)$ \\
\hline \multicolumn{3}{|l|}{ Race, $n$ (\%) } \\
\hline White & $10(71)$ & $6(50)$ \\
\hline Asian & $3(21)$ & $5(42)$ \\
\hline More than one race & $1(7)$ & $1(8)$ \\
\hline BMI percentile, mean (SD) & $49(24.8)$ & $66.7(22.6)$ \\
\hline Normal weight, $n(\%)$ & $12(86)$ & $10(83)$ \\
\hline Overweight/obese, $n$ (\%) & $2(14)$ & $2(17)$ \\
\hline \multicolumn{3}{|c|}{ Body composition in males, mean (SD) } \\
\hline Lean body mass $(\mathrm{kg})^{\mathrm{a}}$ & $47.0(6.5)$ & $60.9(5.3)$ \\
\hline Total \% body fat & $19.9(3.0)$ & $16.4(5.9)$ \\
\hline \multicolumn{3}{|c|}{ Body composition in females, mean (SD) } \\
\hline Lean body mass $(\mathrm{kg})$ & $40.7(10.7)$ & $41.1(6.7)$ \\
\hline Total $\%$ body fat & $27.6(4.7)$ & $26.4(5.9)$ \\
\hline \multicolumn{3}{|c|}{ Baseline peak $\mathrm{VO}_{2}(\mathrm{ml} / \mathrm{min} / \mathrm{kg})$, mean $(\mathrm{SD})$} \\
\hline Male & $50.0(8.1)$ & $45.9(7.2)$ \\
\hline Female & $39.9(4.1)$ & $35.9(4.5)$ \\
\hline \multicolumn{3}{|c|}{ Post-training peak $\mathrm{VO}_{2}(\mathrm{ml} / \mathrm{kg} / \mathrm{min})$, mean $(\mathrm{SD})^{\mathrm{b}}$} \\
\hline Male & $57.2(7.3)$ & $53.1(8.7)$ \\
\hline Female & $45.2(5.2)$ & $40.7(6.4)$ \\
\hline \multicolumn{3}{|c|}{ Baseline spirometry, pre-training, mean (SD) } \\
\hline FVC $\%$ predicted $^{\mathrm{a}}$ & $95.3(10.2)$ & $110(12.9)$ \\
\hline $\mathrm{FEV}_{1} \%$ predicted & $92.8(9.9)$ & $102.8(15.2)$ \\
\hline $\mathrm{FEV}_{1} / \mathrm{FVC} \%$ & $84(5.6)$ & $82.8(6.7)$ \\
\hline \multicolumn{3}{|c|}{ Baseline VENCO $\mathrm{C}_{2}$ slope, mean (SD) } \\
\hline Males & $24.5(1.6)$ & $22.6(5.8)$ \\
\hline Females & $25.1(3.0)$ & $26.1(3.7)$ \\
\hline \multicolumn{3}{|l|}{$A C Q$ mean $(S D)$} \\
\hline Before training & $\mathrm{n} / \mathrm{a}$ & $0.69(1.0)$ \\
\hline Post training & & $0.42(0.50)$ \\
\hline
\end{tabular}

ACQ, Asthma Control Questionnaire; n/a, not applicable; VE/VCO2, ventilation/CO2 production.

${ }^{a} P<0.05$ for differences between groups analyzed by $t$-test. Participants who dropped out were excluded from group analysis.

${ }^{\mathrm{b}} \mathrm{P}<0.05$ for training effect with each group.

participants, indicating that the training effort was effective

$(\mathrm{P}<0.01$; Table 2).

Differences in Leukocyte Subtypes in Blood Count with Acute Exercise Pre- and Post-Exercise Training Intervention

Complete blood counts were obtained during acute exercise challenge at baseline, peak exercise, and $1 \mathrm{~h}$ into recovery before and after the exercise training intervention (Figure 2). There were significant increases in absolute neutrophil count, absolute lymphocyte count, absolute monocyte count, absolute eosinophil count, and absolute basophil count with peak exercise $(P<0.05)$. There was no difference seen before and after exercise training.
Baseline Differences in GR Protein Expression among Leukocyte Subtypes

GR expression was different across leukocyte subtypes in mixed model analysis $(P<0.001)$ at all time points. The expression of GR in eosinophils was significantly higher than that in monocytes, T lymphocytes, basophils, and CD16dim cells (adjusted $P<0.05$ ) across all time points (Figure 3). Multiple comparisons between leukocyte subtypes were almost all significant, except for those between neutrophils and eosinophils; neutrophils and basophils; cd16dim cells and T lymphocytes; and eosinophils and basophils. GR expression was also different across monocyte subsets in mixed model analysis $(P<0.001$; data not shown). 

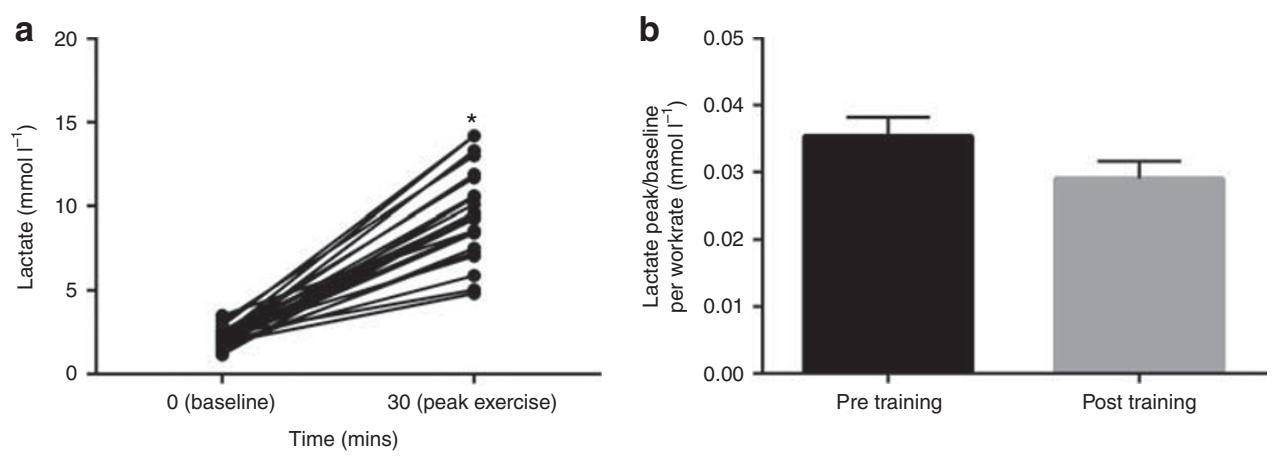

Figure 1. Effect of acute exercise and exercise training intervention on lactate levels. Lactate was significantly increased at peak exercise $\left({ }^{*} P<0.001\right.$; a). There was no significant difference in lactate response to acute exercise (peak/baseline, corrected for work rate) following exercise training $(P=0.74 ; \mathbf{b})$.

a

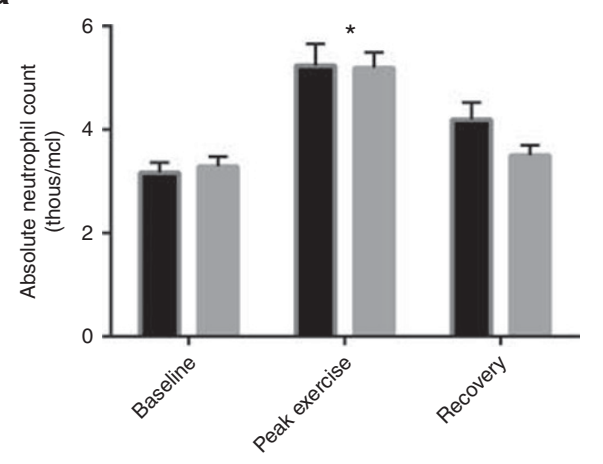

C
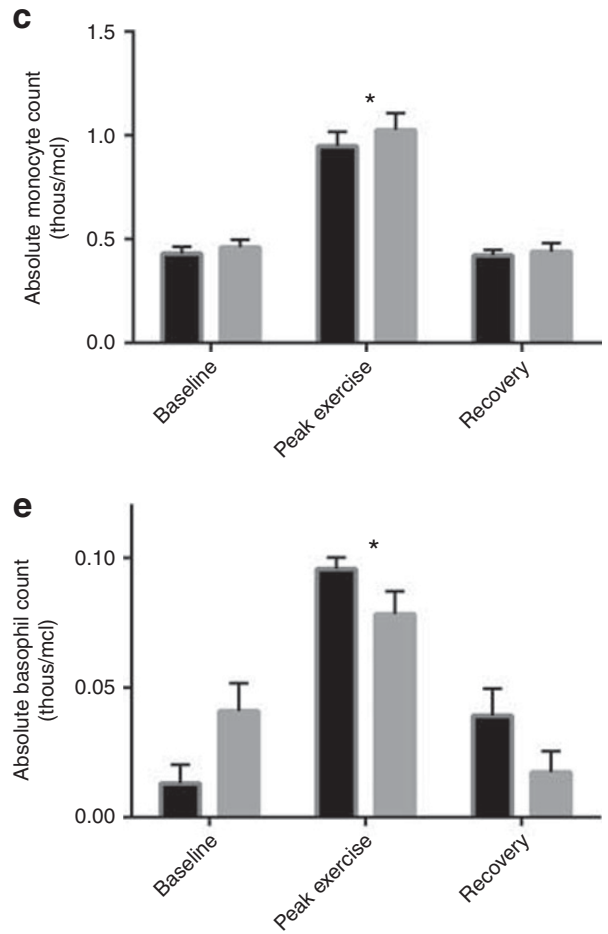

b

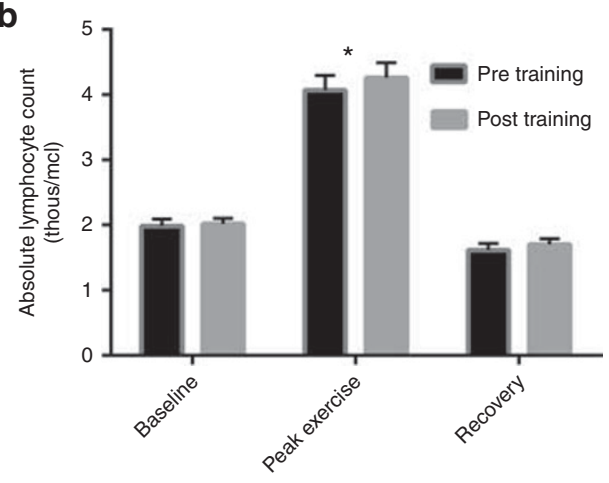

d

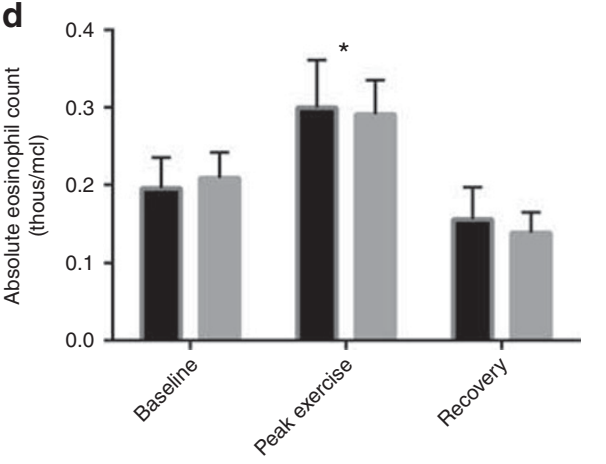

Figure 2. The effect of acute exercise and exercise training on absolute leukocyte counts. Absolute leukocyte counts in response to acute exercise and exercise training intervention in (a) neutrophils, (b) lymphocytes, (c) monocytes, (d) eosinophils, and (e) basophils. There were significant differences between baseline/recovery and peak exercise among all absolute leukocyte counts $\left({ }^{*} P<0.05\right)$. There was no effect seen with exercise training on absolute leukocyte counts. 


\section{Articles | tu et al.}

\section{Effect of Acute Exercise on GR Protein Expression among Leukocyte Subtypes}

GR expression was altered by acute exercise (baseline, peak, and/or 1-h recovery) in monocytes, neutrophils, eosinophils, and basophils using mixed model analysis $(P<0.05$; Figures 4). GR expression was also different during acute exercise in classical and intermediate monocytes in mixed model analysis $(P<0.05$; Figure 5$)$.

\section{Effect of Exercise Training Intervention on GR Protein Expression among Leukocyte Subtypes}

There was a significant effect of exercise training on GR expression in leukocyte subtypes in mixed model analysis $(P<0.05$; Figures 4 and 5$)$. Specifically, there was a significant decrease in GR expression in $\mathrm{T}$ lymphocytes, monocytes, neutrophils, eosinophils, and CD16dim cells following exercise training (adjusted $P<0.05$ ). There was also an effect of exercise training on GR expression in all monocyte subsets in mixed model analysis $(P<0.05)$. Classical, intermediate, and non-classical monocytes had lower GR expression after training (adjusted $P<0.05$ ). There was no significant interaction between acute exercise and training on GR expression in leukocyte subtypes.

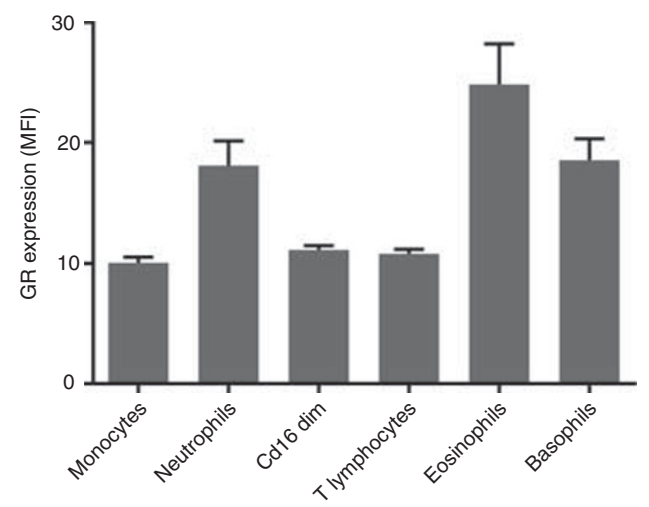

Figure 3. Glucocorticoid receptor (GR) expression differs among leukocyte subtypes. GR expression in leukocyte subtypes at baseline presented as mean (SEM). There are significant differences between GR expression in leukocyte subtypes in almost all comparisons except for neutrophils and eosinophils; neutrophils and basophils; cd16dim cells and T lymphocytes; and eosinophils and basophils.

Figure 4. Effect of acute exercise and exercise training intervention on glucocorticoid receptor (GR) expression in leukocyte subtypes. GR expression in (a) neutrophils, (b) eosinophils, (c) basophils, (d) T lymphocytes, (e) monocytes, and (f) CD16dim cells is presented as the mean (SEM) MFI for each leukocyte subtype at time 0 (baseline), $30 \mathrm{~min}$ (peak exercise), and 90 min (recovery) before and after exercise training. GR expression was altered by acute exercise in monocytes, neutrophils, eosinophils, and basophils $\left({ }^{*} P<0.05\right)$. There was a significant decrease in GR expression at baseline (time 0 ) time 0 after exercise training intervention on T lymphocytes, monocytes, neutrophils, eosinophils, and CD16dim cells (**adjusted $P<0.05$ ).

\section{GR Protein and Gene Expression in Healthy and Asthmatic Adolescents}

Overall, there was no significant difference in GR expression in leukocyte subtypes between healthy and asthmatic participants using flow cytometry and RT-PCR (data not shown).
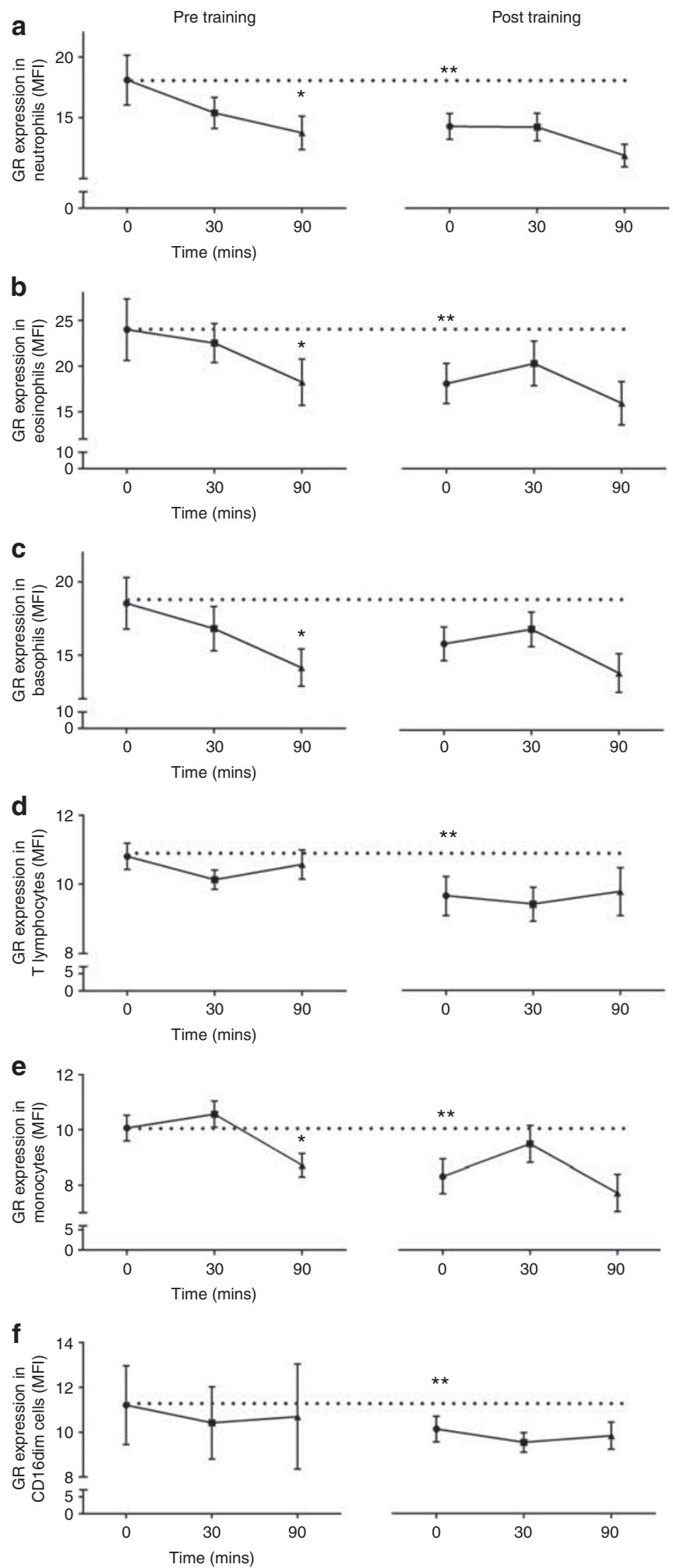

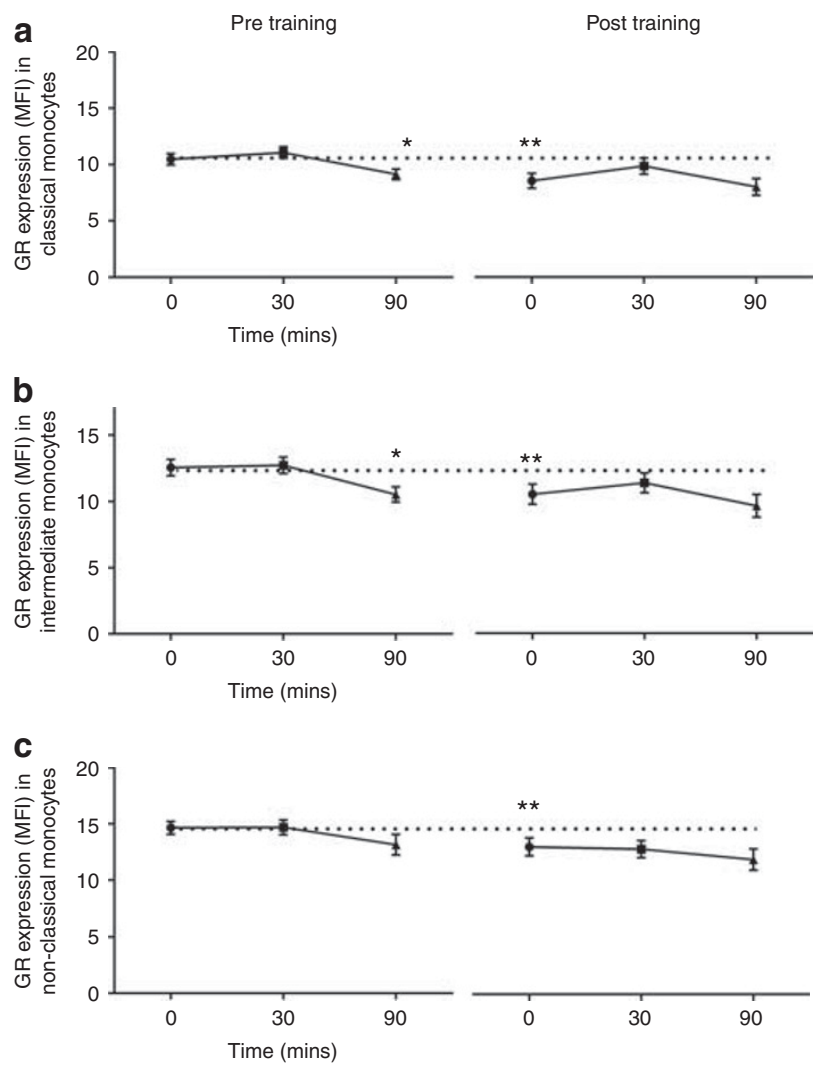

Figure 5. Effect of acute exercise and exercise training intervention on glucocorticoid receptor (GR) expression in monocyte subpopulations. GR expression in (a) classical monocytes, (b) intermediate monocytes, and (c) non-classical monocytes is presented as mean (SEM) MFI for each monocyte subpopulation at time 0 (baseline), 30 min (peak exercise), and $90 \mathrm{~min}$ (recovery) before and after exercise training. There was a significant effect of acute exercise on classical and intermediate monocytes $\left({ }^{*} P<0.05\right)$. GR expression was significantly decreased at baseline after exercise training intervention in all monocyte subpopulations ( ${ }^{* *}$ adjusted $P<0.05$ ).

\section{PBMC Gene Expression of GR and Related Genes}

There was no effect of acute exercise or exercise training intervention on PBMC gene expression of NR3C1, GR $\beta$, TGF $\beta 1$, and TGF $\beta 2$ in both healthy and asthmatic participants (Table 3). We did see an increased expression of HSP70 following acute exercise challenge $(P<0.05)$. There was also a decreased expression of HSP70 at baseline following exercise training $(P<0.05)$.

\section{Cortisol and GR Expression among Leukocyte Subtypes}

There were no significant correlations between cortisol levels (at baseline and after acute exercise before and after exercise training intervention) and GR expression in leukocyte subtypes except for the peak cortisol-level pre-training being negatively correlated with CD16dim expression $(R=-0.51$, $P=0.017$; data not shown).

\section{DISCUSSION}

This is the first prospective study in adolescents to evaluate circulating leukocyte GR expression in response to acute exercise and exercise training. The major novel findings of this study are as follows: (i) the acute exercise challenge significantly reduced GR expression in several leukocyte subtypes despite an increase in the numbers of leukocytes in the circulation (Figure 2) and (ii) the effect of 8 weeks of the exercise training intervention was sustained as demonstrated by a reduction in GR expression in several leukocyte subtypes. We also found that GR expression by flow cytometry was not uniform among leukocyte subtypes, suggesting that the regulation of GR might be tied to particular mechanisms of individual immune cell function. In mRNA derived from the mixed leukocyte population of PBMCs, the exercise training intervention led to a downregulation of HSP70 gene expression (a gene involved in GR function (16)). We found no effect of acute exercise or the exercise training intervention on pulmonary function tests or on ventilatory responses to exercise in either the participants with asthma or the healthy controls. Nor was there a difference in the pattern of leukocyte GR expression in response to acute exercise or the exercise training intervention between the two groups.

\section{Leukocyte GR Protein Expression is Cell-Type-Specific}

Although leukocyte GR is often measured from PBMCs, there is growing evidence that the density and possibly function of glucocorticoids are influenced by the specific immune cell type. In nephrotic syndrome, another chronic disease where steroids are commonly used, Hammad et al. (22) found that expression of GR was significantly lower in $\mathrm{T}$ lymphocytes and monocytes in steroid-resistant patients compared with steroid-sensitive patients and healthy controls, highlighting that GR expression in a specific leukocyte subtype may help determine treatment response. We found that baseline levels of GR expression were substantially and significantly higher in eosinophils, basophils, and neutrophils (Figure 3). The highest expression of GR was found in eosinophils. Conditions characterized by high levels of eosinophils, including nasal polyps and eosinophilic esophagitis, tend to respond favorably to glucocorticoids (23). Eosinophils have a key role in type 2 asthma, contributing to airway inflammation and infiltration (24). Furthermore, current and experimental treatments targeting decreasing eosinophils are used in asthma (25). Basophils are numerous in bronchial biopsies of asthmatics as well as in postmortem specimens of asthmatics; however, the role of basophils in asthma is poorly understood.

\section{Effect of Acute Exercise on GR Protein Expression}

We saw a rapid decrease in GR expression in relation to an acute exercise challenge. This was not correlated with cortisol levels. GR may also decrease in response to other acute stressors, such as shock. Shibata et al. (26) found that children with shock and increased severity of illness had lower GR expression in CD4 and CD8 lymphocytes. Rapid decreases in GR mRNA levels were seen only $30 \mathrm{~min}$ after a forced exercise stress in rats and were associated with changes in DNA methylation and miR-124a levels (27). GR levels on leuko- 


\section{Articles | Lu et al.}

Table 3. Gene expression before and after exercise training in peripheral blood mononuclear cells

\begin{tabular}{|c|c|c|c|c|c|c|}
\hline \multirow[t]{2}{*}{ Gene } & \multicolumn{2}{|c|}{$\begin{array}{l}\text { Pre-training, } \\
\text { relative quantity }\end{array}$} & \multicolumn{2}{|c|}{$\begin{array}{l}\text { Post-training, } \\
\text { relative quantity }\end{array}$} & \multirow[t]{2}{*}{ Training effect, baseline; $P$-value } & \multirow[t]{2}{*}{ Training effect, peak; $P$-value } \\
\hline & Baseline & Peak & Baseline & Peak & & \\
\hline$N R 3 C 1$ (GR) & 1.04 & 1.12 & 1.11 & 1.10 & 0.33 & 0.86 \\
\hline$G R \beta$ & 0.77 & 0.76 & 0.74 & 0.69 & 0.74 & 0.53 \\
\hline TGF $\beta 1$ & 0.75 & 0.76 & 0.75 & 0.76 & 0.83 & 0.88 \\
\hline TFG $\beta 2$ & 0.56 & 0.46 & 0.65 & 0.43 & 0.46 & 0.48 \\
\hline Heat Shock Protein 70 kd & 1.48 & 3.73 & 1.16 & 2.89 & 0.04 & 0.16 \\
\hline
\end{tabular}

GR, glucocorticoid receptor.

Paired $t$-test. Significant values are bolded $(P<0.05)$.

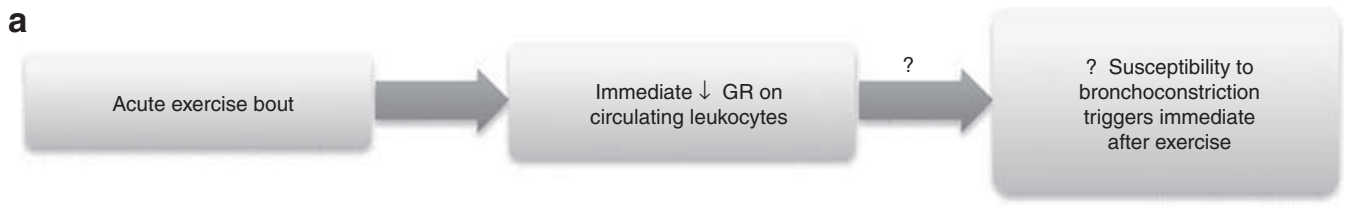

b

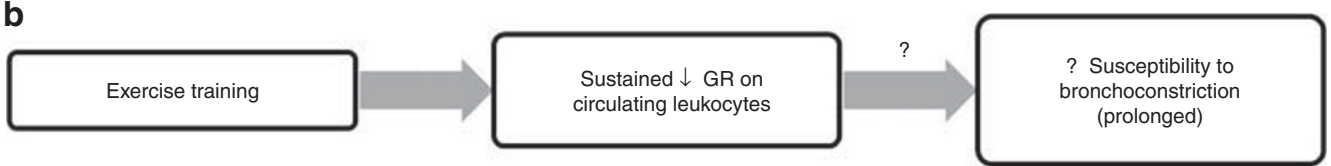

Figure 6. The major findings of the study ((a) acute exercise and (b) exercise training) and possible impacts on health. Exercise is a multifactorial perturbation to cellular homeostasis including the following: changes in $\mathrm{pH}$ and temperature; release of stress cytokines and growth factors; and changes in neuroadrenergic regulation. In the response to an acute bout of exercise, circulating leukocyte GR is immediately reduced in key leukocyte subtypes. This perhaps creates a period of vulnerability in patients with asthma, rendering them more susceptible to additional triggers of bronchoconstriction. Paradoxically, the effect of the longer-term exercise training was a sustained reduction in GR on circulating leukocyte subtypes. This may represent a longerterm downregulation of the GR in response to the repeated elevation in glucocorticoid and other stress hormones (an increasing number of which is now known to alter GR (37)). Ultimately, how this sustained downregulation of leukocyte GR is related to the clinical observation of improved asthma control in fitter children remains unknown.

cytes may also change over a short period of time through, for example, phosphorylation of GR (28).

We speculate that acute downregulation of the GR on leukocytes may represent a period of increased vulnerability to triggers, leading to bronchoconstriction, similar to the increase in susceptibility to upper respiratory tract infections following acute bout of exercise thought to be related to shortterm suppression of the immune system (29).

\section{Effect of Exercise Training Intervention on GR Protein Expression}

We found a significant decrease in GR expression on $\mathrm{T}$ lymphocytes, monocytes, neutrophils, eosinophils, and CD16dim cells following exercise training (Figure 5). Improved fitness has been shown to improve asthma symptoms and airway inflammation in asthmatics. Furthermore, aerobic training has been associated with a decreased need for glucocorticoids in asthmatics (30). Emerging evidence suggest a role for the GR in mediating the anti-inflammatory effects of exercise training. Animal models of asthma suggest that aerobic training is associated with an anti-inflammatory effect through various mechanisms including reduction in NF- $\kappa \beta$ levels (31), GR expression
$(32,33)$, or anti-inflammatory cytokines (34). In an animal asthma model, Silva et al. (32) found that aerobic training increased the expression of GR in the airway smooth muscle, as well as the expression of anti-inflammatory cytokines, leading to decreased airway inflammation and inflammatory mediators. This finding in airway smooth muscle differs from our findings in leukocyte subtypes; however, GR expression and regulation vary considerably between tissues (35).

In one study of subjects undergoing different training regimes, highly trained athletes were found to have lower levels of GR- $\alpha$ mRNA compared with low-trained and untrained subjects in PBMCs (6). In another study of healthy males, exercise training was associated with a significant reduction in GR mRNA, as well as NFK $\beta 1$ in mononuclear cells with concomitant reduction in cytokine concentrations and basal cortisol levels (36).

Given the high prevalence of steroid treatment in many diseases, there is a surprising lack of clinical studies focused on mechanisms of GR regulation. GR expression is decreased following treatment with steroids, but is also decreased following an acute stress (26). Our results showing decreased GR expression in both acute exercise and an exercise intervention illustrate a possible paradox. We found that 
acute exercise is associated with decreased expression of GR and may represent a brief period of increased vulnerability to triggers, leading to bronchoconstriction. Decreased GR is associated with increased severity of illness in critically ill children in the pediatric intensive care unit (26).

We speculate that exercise training (involving repeated bouts of exercise) downregulates the stress response in general, and will render individuals less susceptible to triggers and bronchoconstriction (Figure 6). This healthy adaptation phenomenon may be an example of hormesis, where repeated exposures of a stress, such as acute exercise, can elicit adaptive changes allowing individuals to withstand greater stress (38). Environmental stressors, such as exercise or the microbial environment, may activate the immune system, particularly the innate immune system, and protect against development or worsening of asthma (39). For adolescents prone to asthma, increased tolerance of stress and inflammation may help explain why improving fitness improves asthma control and symptoms.

\section{GR Expression in Asthma}

We found no differences in GR protein expression between healthy controls and adolescents with asthma using flow cytometry. We also did not find any differences in GR mRNA expression between controls and asthmatics, although our sample size of asthmatics was small. This is consistent with previous studies where levels of GR mRNA or protein levels did not differ between healthy and asthmatic participants with varying degrees of severity $(17,40)$. Perisic et al. (40) found that GR-binding affinity in mononuclear cells was decreased, whereas the number of GR was increased in moderate asthmatic adolescents compared with that in mild asthmatics and healthy subjects. The investigators did not examine responsiveness to steroids.

\section{Gene Expression}

We selected a small group of genes known to be involved in the GR pathway. We found that HSP70 gene expression in PBMCs was significantly increased following acute exercise challenge. In addition, we found that baseline levels of HSP70 were decreased after exercise training. HSP70 in skeletal muscle and circulating leukocytes is affected by acute bouts of exercise (41), and it also interacts with GR through partial unfolding that results in GR ligand release and inactivation (16). From our flow cytometry data, it is clear that GR expression varies among different leukocyte subtypes; this might explain why it would be difficult to identify effects of individual leukocyte subtypes in the heterogeneous population of PBMCs. We found no differences in gene expression of NR3C1, GR $\beta$, TGF $\beta 1$, and TGF $\beta 2$ in response to acute or exercise training. We only selected a small group of genes related to glucocorticoid function and therefore could have missed others that were not examined.

\section{Study Limitations}

Although GR expression is only one factor that explains glucocorticoid responsiveness, we did not measure GR function, for example, with dexamethasone stimulation, which could provide further insight into the role of GR in acute exercise and exercise training. Gene expression was performed in PBMCs on a small number of targeted genes, and there may be differences in expression of genes that influence GR that were not tested. Further, the gene expression pattern of specific leukocyte subtypes may not be reflected in the larger PBMC sample. Indeed, we have found that the pattern of gene expression in response to acute exercise among circulating leukocytes is cell-type-specific $(11,19)$. There are data from animal models that even within a specific leukocyte subtype patterns of gene expression differ from cells residing in specific tissues compared with circulating cells (42). In our studies in children, we could only safely access circulating leukocytes, and it is quite possible that gene expression (and, perhaps, GR quantity) differs between the circulating pool and the pulmonary pool of cells. It is noteworthy that the concentration of almost all leukocyte subtypes is much higher in the pulmonary circulation than in the peripheral blood, suggesting a possible unique activation of these cells that are in close contact with potentially harmful mediators (e.g., pathogens and pollutants) in the environment. Additional factors in determining glucocorticoid responsiveness include evaluation of different $\mathrm{GR}$ isoforms at the protein level. GR isoforms can only be identified using western blot analysis of proteins, and a more accurate assessment of the impact of exercise on GR can be carried out by examining protein expression of GR isoforms and whether the localization of those isoforms changes between the cytoplasm and the nucleus with exercise. Another limitation of our study was the ability to detect race or ethnic differences in GR expression in our study population. There are several studies that have reported differential race/ethnic responses to corticosteroids, specifically that AfricanAmerican asthmatics may respond less to corticosteroids compared with other groups (43). Finally, we studied a group of self-selected adolescents with asthma who were relatively fit, and the majority of asthmatics were under good control. We suspect that children with asthma who volunteer for studies involving exercise may represent patients who are more physically active than those who choose not to volunteer. We speculate that differences in GR expression may be evident in asthmatics who are unfit, are more symptomatic, or do not respond to steroids effectively.

\section{CONCLUSIONS}

In summary, we found that an exercise training intervention decreased GR expression in circulating leukocytes in healthy and asthmatic adolescents and may be one mechanism through which improved fitness leads to improved asthma control and symptoms. Future studies should include looking at the effect of exercise on GR function, different GR isoforms, as well as localization of GR between the cytoplasm and the 
nucleus. Finally, this is an exciting time for translational researchers focused on the role of GR in health and disease. Hapgood et al. (37) recently outlined a remarkable set of glucocorticoid-independent mechanisms through which stress, cytokines, and other factors alter the GR and influence its physiological function. Given the multifactorial nature of the effect of exercise on cellular homeostasis (ranging from changes in temperature and $\mathrm{pH}$ to production of stress and growth factors), it is highly likely that some of these newer mechanisms may have a role in the exercise effect on GR in circulating leukocytes.

\section{SUPPLEMENTARY MATERIAL}

Supplementary Material is linked to the online version of the paper at http://www.nature.com/pr

\section{ACKNOWLEDGMENTS}

We thank Annamarie Stehli for statistical analyses and Peter Horvath for laboratory technical assistance.

\section{STATEMENT OF FINANCIAL SUPPORT}

This work was supported by NIH P01-HD048721; the UCI Institute for Clinical and Translational Science (CTSA grant) UL1 TR000153; Children's Hospital of Orange County-University of California, Irvine Child Health Research Award.

Disclosure: The authors declare no conflict of interest.

\section{REFERENCES}

1. Gilbert IA, Fouke JM, McFadden ER. Heat and water flux in the intrathoracic airways and exercise-induced asthma. J Appl Physiol 1987;63:1681-91.

2. Kodesh E, Zaldivar F, Schwindt C, et al. A rat model of exercise-induced asthma: a nonspecific response to a specific immunogen. Am J Physiol Regul Integr Comp Physiol 2011;300:R917-24.

3. Radom-Aizik S, Zaldivar FP Jr., Haddad F, Cooper DM. Impact of brief exercise on circulating monocyte gene and microRNA expression: implications for atherosclerotic vascular disease. Brain Behav Immunol 2014;39:121-9.

4. Cooper DM, Radom-Aizik S, Schwindt CD, Zaldivar F. Dangerous exercise -lessons learned from dysregulated inflammatory responses to physical activity. J Appl Physiol 2007;103:700-9.

5. Cohen S, Janicki-Deverts D, Doyle WJ, et al. Chronic stress, glucocorticoid receptor resistance, inflammation, and disease risk. Proc Natl Acad Sci USA 2012;109:5995-9.

6. Bonifazi M, Mencarelli M, Fedele V, et al. Glucocorticoid receptor mRNA expression in peripheral blood mononuclear cells in high trained compared to low trained athletes and untrained subjects. J Endocrinol Invest 2009;32:816-20.

7. Guldberg-Møller J, Hancox B, Mikkelsen D, Hansen HS, Rasmussen F. Physical fitness and amount of asthma and asthma-like symptoms from childhood to adulthood. Clin Respir J 2015;9:314-21.

8. Eichenberger PA, Diener SN, Kofmehl R, Spengler CM. Effects of exercise training on airway hyperreactivity in asthma: a systematic review and meta-analysis. Sport Med 2013;43:1157-70.

9. Yuryeva K, Saltykova I, Ogorodova L, et al. Expression of adenosine receptors in monocytes from patients with bronchial asthma. Biochem Biophys Res Commun 2015;464:1314-20.

10. Pazdrak K, Kurosky A. Functional proteomics for the characterization of impaired cellular responses to glucocorticoids in asthma. Adv Exp Med Biol 2014;795:255-70.

11. Radom-Aizik S, Zaldivar F Jr., Leu SY, Galassetti P, Cooper DM. Effects of $30 \mathrm{~min}$ of aerobic exercise on gene expression in human neutrophils. J Appl Physiol 2008;104:236-43.
12. Cooper DM, Kaplan M, Baumgarten L, Weiler-Ravell D, Whipp BJ, Wasserman K. Coupling of ventilation and CO_2_ production during exercise in children. Pediatr Res 1987;21:568-72.

13. American Thoracic Society; European Respiratory Society. ATS/ERS recommendations for standardized procedures for the online and offline measurement of exhaled lower respiratory nitric oxide and nasal nitric oxide. 2005Am J Respir Crit Care Med 2005;171:912-30.

14. Juniper EF, Gruffydd-Jones K, Ward S, et al. Asthma Control Questionnaire in children: validation, measurement properties, interpretation. Eur Respir J 2010;36:1410-6.

15. Cooper DM, Weiler-Ravell D, Whipp BJ, Wasserman K. Aerobic parameters of exercise as a function of body size during growth in children. J Appl Physiol 1984;56:628-34.

16. Kirschke E, Goswami D, Southworth D, Griffin PR, Agard DA. Glucocorticoid receptor function regulated by coordinated action of the Hsp90 and Hsp70 chaperone cycles. Cell 2014;157:1685-97.

17. Butler CA, McQuaid S, Taggart CC, et al. Glucocorticoid receptor beta and histone deacetylase 1 and 2 expression in the airways of severe asthma. Thorax 2012;67:392-8.

18. Wen FQ, Kohyama T, Skold CM, et al. Glucocorticoids modulate TGF-beta production. Inflammation 2002;26:279-90.

19. Radom-Aizik S, Zaldivar F, Haddad F, Cooper DM. Impact of brief exercise on peripheral blood NK cell gene and microRNA expression in young adults. J Appl Physiol 2013;114:628-36.

20. Parsons JP, Hallstrand TS, Mastronarde JG, et al. American thoracic society documents an official american thoracic society clinical practice guideline: exercise-induced bronchoconstriction. 2012;187:1016-27.

21. National Asthma Education and Prevention Program. Expert Panel Report 3 (EPR-3): guidelines for the diagnosis and management of asthma-summary report 2007. J Allergy Clin Immunol 2007;120: S94-138.

22. Hammad A, Yahia S, Gouida MS, Bakr A, El-farahaty RM. Low expression of glucocorticoid receptors in children with steroid-resistant nephrotic syndrome. Pediatr Nephrol 2013;28:759-63.

23. Druilhe A, Letuve S, Pretolani M. Glucocorticoid-induced apoptosis in human eosinophils: mechanisms of action. Apoptosis 2003;8:481-95.

24. Kanda A, Driss V, Hornez N, et al. Eosinophil-derived IFN- $\gamma$ induces airway hyperresponsiveness and lung inflammation in the absence of lymphocytes. J Allergy Clin Immunol 2009;124:e9.

25. Possa SS, Leick EA, Prado CM, Martins MA, Tibério IFLC. Eosinophilic inflammation in allergic asthma. Front Pharmacol 2013;4:46.

26. Shibata ARO, Troster EJ, Wong HR. Glucocorticoid receptor expression in peripheral WBCs of critically ill children. Pediatr Crit Care Med 2015;16:e132-40.

27. Mifsud KR, Saunderson EA, Spiers H, et al. Rapid down-regulation of glucocorticoid receptor gene expression in the dentate gyrus after acute stress in vivo: role of DNA methylation and microRNA activity. Neuroendocrinology 2017;104:157-69.

28. Galliher-Beckley AJ, Cidlowski JA. Emerging roles of glucocorticoid receptor phosphorylation in modulating glucocorticoid hormone action in health and disease. IUBMB Life 2009;61:979-86.

29. Kakanis MW, Peake J, Brenu EW, et al. The open window of susceptibility to infection after acute exercise in healthy young male elite athletes. Exerc Immunol Rev 2010;16:119-37.

30. Fanelli A, Cabral AL, Neder JA, Martins MA, Carvalho CR. Exercise training on disease control and quality of life in asthmatic children. Med Sci Sports Exerc 2007;39:1474-80.

31. Pastva A, Estell K, Schoeb TR, Atkinson TP, Schwiebert LM. Aerobic exercise attenuates airway inflammatory responses in a mouse model of atopic asthma. J Immunol 2004;172:4520-6.

32. Silva RA, Almeida FM, Olivo CR, Saraiva-Romanholo BM, Martins MA, Carvalho CR. Exercise reverses OVA-induced inhibition of glucocorticoid receptor and increases anti-inflammatory cytokines in asthma. Scand J Med Sci Sport 2016;26:82-92. 
33. Pastva A, Estell K, Schoeb TR, Schwiebert LM. RU486 blocks the antiinflammatory effects of exercise in a murine model of allergen-induced pulmonary inflammation. Brain Behav Immunol 2005;19:413-22.

34. Silva RA, Vieira RP, Duarte AC, et al. Aerobic training reverses airway inflammation and remodelling in an asthma murine model. Eur Respir J 2010;35:994-1002.

35. Kalinyak JE, Dorin RI, Hoffman AR, Perlman AJ. Tissue-specific regulation of glucocorticoid receptor mRNA by dexamethasone. J Biol Chem 1987;262:10441-4.

36. Silva SE, Longui CA, Rocha MN, et al. Prolonged physical training decreases mRNA levels of glucocorticoid receptor and inflammatory genes. Horm Res Paediatr 2010;74:6-14.

37. Hapgood JP, Avenant C, Moliki JM. Glucocorticoid-independent modulation of GR activity: implications for immunotherapy. Pharmacol Ther 2016;165:93-113.
38. Ji LL, Kang C, Zhang Y. Exercise-induced hormesis and skeletal muscle health. Free Radic Biol Med 2016;98:113-22.

39. Stein MM, Hrusch CL, Gozdz J, et al. Innate immunity and asthma risk in amish and hutterite farm children. N Engl J Med 2016;375:411-21.

40. Perisic T, Sreckovic M, Matic G. Modulation of glucocorticoid receptor function and expression in adolescent moderate asthma. Respiration 2009;77:70-5.

41. Walsh RC, Koukoulas I, Garnham A, Moseley PL, Hargreaves M, Febbraio MA. Exercise increases serum Hsp72 in humans. Cell Stress Chaperones 2001;6:386-93.

42. Takeda K, Nakayama M, Sakaki M, et al. IFN- $\gamma$ production by lung NK cells is critical for the natural resistance to pulmonary metastasis of B16 melanoma in mice. J Leukoc Biol 2011;90:777-85.

43. Federico MJ, Covar RA, Brown EE, Leung DYM, Spahn JD. Racial differences in T-lymphocyte response to glucocorticoids. Chest 2005;127: 571-8. 